DOI: $10.1515 /$ hssr -2016-0004

\title{
Recalculating the White Page-GPS Love in Comme dans un film des frères Coen
}

\author{
Valerie Hastings ${ }^{*}$ \\ University of North Georgia, USA
}

\begin{abstract}
Hastings reads the novel Comme dans un film des frères Coen (2010) by Bertrand Gervais as addressing both the midlife and the blank page crisis. Indeed, the main character of this novel is a writer in his fifties who still suffers from the failure of his last novel ignored by the critics. Disenchanted, he slowly enters a world of fantasy, and falls in love with the voice of his GPS he called Gwyneth "parle trop" (speaks too much) therefore recalling the name of the actress with the same name. He gradually loses contact with his wife and his son, a successful painter, and is transformed into "the man who was not there" another character from a movie by the Coen brothers entitled The Barber: the man who was not there. Hastings asks: How could one get lost with a GPS? After the main character had initially bought his GPS for a trip in Australia in order to find his way, it started to go beyond its role as a road guide and questioned where he was in his relationship with his wife, in his career as a writer, and in his skin as a mature man. Not only was the GPS not fulfilling its purpose but also it started to ruin a fragile relationship hoping to find its way back to love during a last minute trip in Australia. Even after destroying the annoying talkative GPS, it continued to disrupt the couple in the plane on the way back to Canada. As much as Gwyneth the GPS is synonymous with escape and freedom, it is also showing the main character the wrong way, the way out of his reality, out of his family and out of his life. His attempts to free himself from Gwyneth are worthless, her image is still there, haunting his thoughts like images
\end{abstract}

\footnotetext{
* University of North Georgia, Department of Modern and Classical Languages,82 College Circle Dahlonega, GA30597 United States, Valerie.Hastings@ung.edu
} 
HSS, vol. V, no. 1(2016): 53-72

from a movie. But the displacement happens at another level than just the diegetic one. The confrontation of the text with moving images has consequences on the shape of the text itself. The mapping of the text on the page is influenced by this amalgam. The white page becomes a space where words are rearranged in different ways, some of which suggest poetry, other cartoons or cinematic images. The displacement of literature in areas that were previously foreign to it is at the heart of creative activity, and determines its renewal. Hastings presents the consequences resulting from the confrontation with the GPS, both on the mapping of one's identity as well as the mapping and the shaping of the text itself.

Keywords

Representation, Images, Mapping, Real,Virtual

Comme dans un film des frères Coen ${ }^{1}$ by Bertrand Gervais announces itself on its front cover asa novel. It is nonethelessa new typeofnovel, a novel / film, neithera film adaptationnora novelization ${ }^{2}$. Remy, like Barton Fink, ${ }^{3}$ is a writer in his fifties frustrated by the failure of his last novel Argyle Street facing at the same time his midlife and a blank page crisis. Disenchanted, he slowly enters a world of fantasy, and falls in love with his GPS he calls Gwyneth "parle trop" (in French "speaks too much") recalling phonetically the name of the actress Gwyneth Paltrow. His reality filled with new fantasized images, he gradually loses contact with his wife ${ }^{5}$ and his son, a successful painter, and slowly becomes "the man who was not there" another character from a movie by the Coen brothers entitled The Barber: The man who was not there ${ }^{6}$. How could one get lost if equipped with a GPS? After the main character had initially got the navigator system for a trip in Australia, it started to go beyond its role as a simple road guide and questioned where he was, not on the road, but in his relationship with his wife, in his career as a writer, and in his own skin as a mature man. Not only was the GPS not fulfilling its purpose but it also started to ruin a fragile relationship hopping to find its way back to love during a last minute trip in Australia. Even after destroying the annoying talkative GPS, it continued to disrupt the couple in the plane on the way back to Canada where Gwyneth the GPS reappeared first in the shape of a flight attendant, ${ }^{7}$ then under Estelle 
A., ${ }^{8}$ a model of his son, later as a poetess pretending to be Sylvia Plath, ${ }^{9}$ and finally as Elisabeth Poignard convinced to be a protagonist in Remy's book Argyle Street. All those versions of Gwyneth, recalling images from different roles played by the actress Gwyneth Paltrow are showing the way into the imaginary, a known path through filmic memories. However, as much as Gwyneth the GPS is synonym of escape and freedom, it is also showing the main character the way out of his reality, out of his family and out of his life. His attempts to free himself from Gwyneth are all worthless; her image is always there, haunting his thoughts like images from a movie. But the displacement happens at a level other than just the diegetic one. The confrontation of the text with moving images has consequences on the shape of the text itself. The mapping of the text on the page is influenced by this amalgam. The white page becomes a space where words are rearranged in different ways, some of which suggest poetry, other cartoons or cinematic images. The displacement of literature in areas that were previously foreign to it is at the heart of creative activity, and determines its renewal in a contemporary epistemology which favors iconography. Comme dans un film des frères Coen is a different type of book, a novel partly about movies but also a book behaving like a movie, it forces us to recalculate our position as a reader/spectator and also to recalculate the positioning of literature in a world more and more dominated by moving images. This study will analyze the consequences resulting from the confrontation with the GPS, both on the mapping of one's identity as well as the mapping and the shaping of the text itself.

"Recalculating..." That could summarize what the main protagonist Remy is forced to do in a changing world where images are present everywhere. This presence, influenced greatly by what some call the pictorial turn ${ }^{10}$ to embody the raising of pictorial media in the Twentieth Century, has raised questions about the status of images: "What precisely are we being told when it is said that there is no longer any reality but only images?" (Rancière, 2007: 1). This dynamic between text and images is announced in Gervais' novel in the title itself "Commedans un film des frères Coen" which in English could be translated as "Like in a movie from the Coen brothers", and furthermore with the competition which takes place between a son (an adopted one), 
a successful painter, and the father, the main character, a writer whose last book was a complete failure. Remy complains: "I feel like Barton Fink in front of his typewriter, unable to write the scenario ordered" (69) while his son "is producing like crazy" (70). This situation leads to a rethinking of the capacities of language and literature for world-making and global positioning especially since the narrator affirms "words are our way of being in the world" (28). The no longer inspired writer often confuses his identity with what he calls his "cahiers" 11 which have been stolen by his son, he affirms: "Without my notebooks I am dead [...] like a man who has lost his memory" (106). Later he explains: "My notebooks are my flesh, the very substance of my being. Without them I am nothing. My computer is only a machine [...] they are my memory alive" (117). Alexandre, his son, challenges this naïve belief that one's life and identity could be summarized in those books, an inadequate mode of representation in his opinion: "Alexandre finds them obsolete. $\mathrm{He}$ makes fun of words, and their monochrome shells. The long sentences stretching out in my notebook pages are worms for him [...] he is looking for purer forms [...] He wants nothing to be cerebral. Spontaneity is his only principal" (72). After the disappearance of those notebooks for which Remy blames his son, he is therefore left with what he calls "The last notebook" (also the title of chapter four), as if he was writing the last page of his life, very aware of his own finitude. He calls himself a "has been ${ }^{12 "}$ "(14) and expresses his anxiety in particular when he is at the hospital for a colonoscopy, in chapter seven entitled for the occasion "Obituary Column". Thus his replacement by his son seems inevitable, he is dying while his son is young and vibrant; his sexual life is over, while his son is a popular artist working in close relationship with young and beautiful women. Dedicating his work to Donald Barthelme, Gervais uses a quote from the novel The Dead Father ${ }^{13}$. In this strange story published in 1975, the father not really dead or alive, neither a machine nor a human figure ${ }^{14}$ is dragged with a cable by some of his children to a mysterious place uncovered at the end of the novel, his burial spot. This is not without resonance with Gervais' book in which the father seems to have been assassinated more than simply replaced by his son the painter. Is Gervais' novel therefore an assassination of the words by images, and more specifically by the moving images? Indeed, 
HSS, vol. V, no. 1(2016): 53-72

what kind of images are we dealing with? What power do those moving images have?

Giorgio Agamben writes On Guy Debord's Films:

First, man is the only being who is interested in images as such. Animals are very interested in images, but only to the extent that they are fooled. You can show a male fish the image of a female fish and the male will eject his sperm; you can fool a bird with the image of another bird, in order to trap it. But when the animal realizes it's dealing with an image, it loses interest completely. Now, man is an animal who is interested in images when he has recognized them as such. That's why he is interested in painting and why he goes to the cinema. (Agamben, 2002: 314)

Although the main character in Gervais' novel is actually aware of the nature of the image taken straight from his imaginary, from his filmic memory, this image will nevertheless not only rule his life as a writer as he is unable to write, but also destroy his family life. He asserts about Gwyneth: "Nothing comes from the absence. / No written record. No form friendly. / Gwyneth, I beg you, do something. Put your varnished wood finger on my forehead." (99) But nothing will come from the image of Gwyneth Paltrow as Margot with her wood finger in the movie The Royal Tenenbaums. On the other hand, he soon realizes "that the departure of Carole was real." (101) The understanding that his life is escaping him emphasizes the danger of a society where "THE SPECTACLE APPEARS at once as society itself." In the Society of the Spectacle, "all that once was directly lived has become mere representation", in this world, "truth is a moment of falsehood" (Debord, 2013: 14).

In numerous scenes, Remy is indeed faced with several levels of simulation. Baudrillard reminds us in his book Simulacra and Simulations what those various levels of simulation are. The first level would be the one in which the representation of reality (novel, painting, map, movie...) is presented as an artifice. At a second level of simulation, the boundaries between reality and representation become porous. Baudrillard takes as an example the Borges fable in which the map is so detailed that it covers the territory completely and perfectly. Its precision makes it no longer possible to distinguish between it and the reality it covers, as a 
GPS tends to represent the territory so perfectly that it sometimes leads us to take the path shown onscreen against all common sense. At a third level of simulation, Baudrillard goes further. At this level the origin itself has disappeared, reality no longer precedes the model but it is the model that preexists. At this stage, it is therefore the map that precedes the territory. It is no longer a matter of porosity between reality and its representation, as in the second level of simulation, the reversal cannot occur anymore since the two poles, reality and representation have been replaced by an "hyperreality" reproducing itself outside any issues of mimesis and representation. In the first two levels, it is still possible to distinguish true from false, which is no longer the case in the third degree of simulation, the real cannot be a point of resistance against which one can measure the strength of the simulation. The "discreet charm of the second-order simulacra" Baudrillard tells us, most likely referring to the film The discreet charm of the bourgeoisie, has lost his fascinating power compared to the omnipotence of an hyperreality in which it is no longer possible to refer to a solid reality as the starting point ${ }^{15}$. The precession of the simulacra prohibits starting from any fixed point to conclude for a reversal between reality and simulation. The origin is no longer visible. Baudrillard identifies the stakes of this evolution in the transformation of our relationship with images:

Such would be the successive phases of the image:

- It is the reflection of a profound reality

- It masks and denatures a profound reality

- It masks the absence of a profound reality

- It has no relation to any reality whatsoever: it is its own pure simulacrum. (Baudrillard, 1981: 17)

Remy faces the image at those different levels. First, in the hotel room, while watching the news, the narrator describes the various events in a factual manner having previously stated: "I feel as if I was in a fantasy world" (12). The various events described therein, including the death of a man on the road by a Kangaroo or the one of the two brothers gone on a trip to photograph a glacier, do not seem real to him. Facts such as "Australia has eight of the twelve most venomous snakes 
in the world" (12), in the same vein as the paragraph preceding these newscasts, in which the life of the kangaroo is described as it would be scientifically in a documentary, confront others such as "a UFO was photographed last night near Melbourne and authorities are baffled" (12). However the truth of these claims, the scientific description and extraterrestrial matter, is not measurable. We recognize here the third phase of the image, which according to Baudrillard "masks the absence of profound reality." (Baudrillard, 1981: 17)

The simulations of the first two orders (the artificial representation of reality on the one hand, being a "sacrament" that is to say a good appearance or a "curse", and the other resulting from the blurring of the boundary between the simulacrum and the real) correspond to the first three phases of the image previously described. In the case of the narrator, the GPS appears first as the layout of the road on the screen and although it covers the territory almost perfectly, the concept of representation still persists. Indeed, the confusion between the territory and the map is possible, but these two poles are preserved. Likewise, Gwyneth the GPS can "do" all the voices so perfectly that it becomes a "formidable presence" (11). At this second level, the boundary between reality and representation is permeable, the GPS starts therefore to converse with the couple and does not follow the line of its trajectory. Thus the woman's voice impeccably imitated by the GPS becomes that of Gwyneth. Representation is so close to the real that "everything is upside down" (11), the map becomes the territory.

However, it reaches a different level of simulation (third level) when the GPS is compared not to reality but to another simulation mode. Indeed, the narrator instead of noticing the analogy between the map outlined by the GPS and the real territory, claims "it's like a video game" (9). The map becomes a video game. The real territory has completely disappeared from the equation, "It is no longer about map and territory." (Baudrillard, 1981: 10) We are therefore at the third level of simulation, the one of the "pure simulacrum" (Baudrillard, 1981: 17), the one where the fantasized voice, designed for the GPS, will not generate other images taken from the real but other fantasized images including film images. The narrator in fact notices: "It is at the third level that I no longer know what to do." (48) In this context of images generating other 
images, the narrator affirms that he has "never felt so lost" (23) and paradoxically especially since he has been using his GPS. He concludes that this world where everything is upside down, is "really" not "a country for an old man" (23), recalling the title of a film by the Coen brothers. In this world where everything is a perfect simulation and where all is dissolved, Remy's identity is no exception, it is therefore forced to "recalculate recalculateRecalculate ..." (34)

The difference between an image and reality pushes Remy to ask his wife: "What separates us from animals? / Not much if I listen to Carole ... / It's culture, it's art" (104). Men's relationship to moving images is raising the question of the border between human and what Agamben calls "the animal" and seems to be a determining factor in the search for a proper of human being, according to Agamben: "Man is a moviegoing animal" (Agamben, 2002: 314). The power of moving images is underlined also in another scene in the Chapter entitled "Mirage". The narrator is intruding like a thief in his son's workshop in the basement of their house. There, he finds a tape with his son's handwriting, entitled Estelle A. and he decides to watch it: "I close my eyes, count to five and open them, ready for any eventuality, I open them and already, the image is moving" (75). What he sees on the screen is Estelle or Gwyneth undressing herself in front of his son attempting to draw her "to imitate in vain the arc drawn by her skirt as it is flying before it hits the ground" (79). He wonders what his son is "waiting for", why being so suborned? Why drawing "in vain" instead of doing other things he would do in this situation? His son is clearly limited by his medium to represent what he sees, he "does not have enough papers" notices the narrator, he does not draw fast enough to capture this life, this movement in French "sur le vif"16 (80). Those drawings, fixed images, are no more than words able to accomplish a miracle: "No words can describe what is felt when one gets close to perfection" (77). But that is without counting on what happens next, an event he calls "a miracle that he cannot explain [...] an event which staggered him" (81). A ray of sunlight "had crossed the workshop to land on Estelle's head". The sun not being on that side of the house at this time, he concludes that what is happening is in "a different frame or shot" (82) using vocabulary from cinema to describe the location of this miracle in a different dimension. The mirage 
becomes a miracle, this concrete happening, the ray of sunlight, cannot be assimilated to pure simulacrum. More than any other means of representation, filmic images seem able to accomplish a miracle. Thus what is so specific to those filmic images? This is the question asked by Deleuze in Cinema 1 and Cinema 2. Heidegger defined modernity as the representation era. For him, the essence of the world is to be given to the subject in representation; Modernity is the time of representation so it is also the time for technique and science, since the world as an object of representation is also an object of calculus and masterizing. However a camera is not a machine that installs the gaze of a subject-spectator in front of a world-image, these movement-images are constitutive of a non-centered universe where perception is a-subjective, ${ }^{17}$ a universe where an image is perception itself because of the equivalence between light and movement. Thus,Deleuze argues that if the camera seems to fit perfectly with Heidegger's thesis about modernity as the era of representation, it is due to a false understanding of cinema as a technical art that would reduce man to a subject, as the world becomes an image. What escapes the painter Alexandre or Remy the writer, is what Deleuze calls the movement-image in Cinema 1; because Cinema is not a succession of images and is a medium "capable of thinking the production of the new"18 (Deleuze, 1986:7), it is capable of accomplishing miracles in a different time frame. But how is time mapped onto space and more specifically how is the passing of time mapped onto the space of the white page? The constant changes or what Deleuze calls "becoming" cannot be represented onto space. The time it is inscribed in is not one that can be represented vertically (past- presentfuture) but a time which is vertical, often represented as a cone, and that Deleuze calls "duration" to use Bergson's terminology. Duration is a synonym of becoming and as Bergson explains: "Time isinventionoritisnothing at all” (Bergson, 1913: 341). Therefore, starting from a machine like a camera and/or a GPS in this novel, what do you get? Gervais will go as far as to say "a complete invention", 19 one due to confrontation between the inevitable ending of the body machine and the other machine, the one that does not stop (in fact the GPS does not stop talking or working as a it continues to generate Gwyneth's images even after its destruction). The GPS is indeed at the same time a 
"marvelous presence" (11) and a representation of the real.

The moving image is therefore confronted with the text at multiple levels, first at an intradiegetic one, through the confrontation between the unsuccessful writer and the triumph of his son the painter, but also at an extradiegetic level through the influence of the filmic image on the configuration of the text itself. In fact, the novel is divided into eight chapters themselves divided into several parts, resembling small thumbnails imitating the form of comics or like little vignettes that could be part of a movie script, each representing a different ongoing story (the story of their wedding, the story of his friend "Oulipien"20, the story from news on TV, the story from the movie he is watching, his own story...), as if we were a reader / watcher going from one shot to the next with flashbacks, the camera being located mainly in the narrator's head, like a subjective camera. Those small pieces of text in succession (each on a different story) resemble a continuous scrolling of images in a fast or slow motion. The visual aspect of the text becomes crucial to the understanding of the story itself, typographical changes are used, visual GPS symbols appear next to all the voices Remy and Carole can choose from, the text sometimes disappears to leave the background of the white page, sometimes takes the shape of a cartoon, a scenario, or a poetic form.

This metamorphosis of the text is directly related to the porosity of borders between different levels of representation. Mallarmé was already thinking about cinema in his effort to find new ways of reading. In fact, in the context of a question about illustrations, he stated: "I'm for no illustration, all evoked in a book having to happen in the reader's mind, but if you use photographs, why not go straight to cinema, which will eventually replace images and text, preferably"21 (Mallarmé, 2003: 668). Crossing borders between media seems to be at the core of Gervais' novel but other borders are also mentioned and in particular the one between human and animal. The names of the first cameras vitascope, animatograph, biographer, kinetoscope, verascope already associated this new instrument with the capture of life.It seems natural therefore that the film finds its origin in attempts to capture the animal movement. Muybridge attempted to show a horse's legs in motion. Lippit claims that all technology, and more specifically film allows for the mourning of 
animals' disappearance. This is interesting especially in light of the treatment of the animal by Gervais in this book. Animals are mentioned first of all at the beginning of the novel when the couple driving on the road in Australia, attempts to ask their GPS Gwyneth where to find a Kangaroo, a question followed of course by "a long silence" (14). Kangaroos are mentioned again on the TV news in Australia, announcing the death of a man on the road after hitting a Kangaroo. After watching the news, the narrator claims to have found the title for his next novel "Death by a Kangaroo"(10). Ironically later, after his wife's ultimatum to choose between her and the GPS, the narrator hurts with his fast car, "a Kangaroo / a real one"(23). Almost the same scenario as the one in the TV news at the beginning of the novel is repeated except for the conclusion: "I almost killed a Kangaroo, an innocent animal. Me. It was not a dream" (33). But a Kangaroo is not just an animal, it is also a word for a certain type of sweaters, which happen to be those worn by the skaters painted by his son Alexandre. In fact, one skater at the end of the novel will be the victim of a car accident, just like the Kangaroo at the beginning of the novel, in a scene which is almost a rewriting of the first one. The same onomatopoeia is used "THOMB" and the narrator who was "taking a turn very fast [...] heard a dull sound. Thomb! / I had just hit something. / I looked into the rear mirror. / A skater wearing a black kangaroo. Thomb?' (205) The repetition of the scene works like a flashback in a movie. The use of the visual aspect of the onomatopoeia and the disposition of the text on the white page is another instance where the image-movement is present in this text. When Remy asks his wife what "separates us from the animal?" (104) her answer is "not much". The transgression of the animal border parallels the transgressions of the borders between media. The moving image and the text merge and the porous border between man and animal becomes collateral to the fragile boundaries between genres of representation. In fact, these border crossings are the very condition to renew texts and animate them, the only path towards creativity and freedom, as the narrator states when he compares himself with a free animal, but one who does not know yet the way to new dimensions: "Exhaustion is around the corner. I feel like an animal whose chain has just broken, and who does not know what to do to save himself' (121). 
This "exhaustion" is the result of his failure as a writer in search for new concepts and new ideas. At times, his disenchantment with Gwyneth could be interpreted as a renunciation in the power of the image and ultimately in the power of art: "Nothing comes from this absence. / No written trace" (99). However, the writer finds refuge with the omnipresence of Gwyneth, an image-movement and «a marvelous presence » (11), and also with his friend Hubert "oulipien". The displacement of literature in areas that were previously foreign to it is at the heart of the creative activity, and determines its renewal. Cinema in the case of this novel is treated as a constraint ${ }^{22}$. Indeed, the question of coercion as a necessary tool in the process of setting up new worlds is underlined both through the effort of formatting the text, but also because the narrative triggers the search for all those filmic images suggested within it. The confrontation between the animated images and the text occurs thus at multiple levels, diegetic and extra diegetic, the merging of the two means of representation alters the configuration, the shaping of the text itself. This phenomenon of media and genre crossings is revealing of a paradigm shift well described by Jacques Rancière in his book The Future of the Images. Hierarchical distinctions between proper and improper media are abandoned and the overlapping between them is the symptom of the emergence of a new regime. In his book, Jacques Rancière argues in the last chapter entitled 'Are Some Things Unrepresentable?' that there is no unrepresentable, since art is now guided by a new principle: "a principle of 'each to everyone else's", and therefore marked by hybridity. This new regime "the aesthetic regime" (Rancière, 2007: 13) generates works of art in which predominates experimenting with new plastic ways. Jacques Rancière explains the necessity for the collapsing of borders between means of representation:

The anti-mimetic aesthetic revolution is not some 'each to his own' confining each art to its own peculiar medium. On the contrary, it is a principle of 'each to everyone else's'. [...] This does not mean words on one side, forms on the other. It means quite the opposite: the abolition of the principle that allocated the place and means of each, separating the art of word from that of forms, temporal arts from 
HSS, vol. V, no. 1(2016): 53-72

spatial arts. It means the constitution of a shared surface in place of separate spheres of imitation. (Rancière, 2007: 104-105)

The collapsing of the cinematic-image with the text in the novel Gervais fits well in the context of this paradigm shift. Making the impossible possible and rendering visible that which is invisible (persons, places, objects) is the goal at stakes. This attests to a change of attitude towards literature, language and culture, most importantly in respect to the benefits of using visual media and in particular the animated image in literature.

Gervais' text highlights the transformative power of art and confronts any apocalyptic scenarios with a mutation, a "transfiguration" (113), "a world of pure forms in constant metamorphosis" (68). The metamorphic power of art opposes the anti-productive emptiness highlighted by Baudrillard. For him, we cannot get out of a "death system" (Baudrillard, 1981: 11), everything is built around the absence of the real (that is its death). If producing a solution is still a possibility for Debord 23 , it is unnecessary in Baudrillard's system since any attempt at rebellion is automatically already reabsorbed in the whole of the simulation without limits. But between Baudrillard and Debord there is a third way, that of Deleuze. It is the notion of becoming that is missing in the pessimistic analysis of Baudrillard. It is in fact possible to see a line of flight in this totalizing system. This line of flight is what Deleuze chooses to follow especially in Mille Plateaux. Deleuze confronts the apocalyptic hyperreality with the power of life as permanent becoming. The metamorphic strength as well as the becomings of becomings all encompasses what Deleuze calls a plane of immanence: "the plane of immanence is pre-philosophical, and does not already operate with concepts ${ }^{24}$." (Deleuze andGuattari, 1991: 44). The existence or disappearance of a center of gravity is meaningless in a system that is not only the result of an implosion of meaning but a system of differentiation resulting in the production of a limitless becoming. Deleuze explains: "It is the power of a non-organic life, the one that may be in a drawing line, writing or music. It is these bodies that die, not life 25." (Deleuze, 1988: 20) The repetition is not the return to the same, or to an origin, but it is neither a vain repetition, a repetition of a repetition that would generate nothing but itself. When "the mind is empty," it "opens a world" (68) of metamorphoses, when Remy, in his son's art 
studio, "closes his eyes, counts to five and opens them ready for any eventuality," he discovers that "the image is already in motion" (75) contrasting with the "void left by what Alexander stole", the mapping of the words on the white page also changes at the same time. Repetition is not just a return, there was a transformation into something new. Remy wonders: "What is an accident? / Where does it begin and where does it end? When do we know it happened? / What will it mean? / Bodies move into space, they bump against each other, get closer and farther apart in a macabre dance. / Who will tell me what happened?" (205) What has happened is a transformation, a metamorphosis. It takes place in fact just after this questioning in almost an exact repetition of the original accident in Australia at the beginning of the novel, but this time with a skater.

Let us return to the scene at the beginning of the novel when Remy hits a kangaroo while driving his car, as the onomatopoeia that serves as a flashback invites us to. We could retroactively consider the narrator as already dead from the beginning. In fact, he himself insists that if the animal "was a little larger, the accident could have been fatal." (33) The narrator also affirms: "I'm dead without my notebooks [...] My own son betrayed me! / killed me. For it is not allowed to doubt it. / I am dead." (106-108). Because "Alexander is guilty" (100) of that murder, Remy could be a ghost, hence the statement: "The landscape lives within me as much as I haunt it." (107). Therefore, is it possible that his desire to "follow a trail, to get in tune with what goes through every word" (112), or to follow the filmic image of Gwyneth ultimately could be summarized into a ghost hunt "without importance" (107). His wife affirms that she does not have "a husband, but a ghost. [...] I feel like I am living with a ghost. [...] A spirit without a body. This is unbearable. I do not like playing the spectator." (89) Indeed, the terms "spectrum", "spectral", "spectator", "performance" have the same root. An idea widely exploited by Derrida who affirmed that "technology multiplies the power of ghosts." But the crime, namely the theft and the destruction of the notebooks by Alexander never happened, "they were there intact all this time." (209) The murderer has never been one $^{26}$. There was no victim either. The man on the "National Interstate" whose car "hit a kangaroo" and "rolled over multiple times before crashing against a tree" (12-13) on the television news in Australia "died" but Remy survived his accident, he "feared for a moment that the car was going to 
roll over [...] but it remained on its four tires." (33) We could also consider the dead animal, the kangaroo overthrown by Remy in his accident as a prophecy of Remy's fate, the animal would be an image revealing the truth it is negating such as explained in Debord's work, especially Panegyric. But Remy survives his accident at the end of the novel and the victim is a young boy wearing a special hooded sweater called a kangaroo. Should this third repetition of an accident with a kangaroo be considered a reversal of a reversal? Was the spectator falsely passive? Has he become an emancipated spectator?

Reading Marx, it is interesting to note that he had already noted in the very mechanism of the vision, the same phenomenon as in the capitalist system. Even if the spectacle was unmasked, it would still be the first illusion. The disappearance of the spectacle cannot result in a return to truth as Debord has hoped. Similarly the work of Baudrillard, which goes further than Debord taking into account the illusion of the illusion, remains nevertheless nostalgic. Indeed, through his recollection of the history of the image described in its successive stages, moving away from a reference point to the point that it has become invisible. But this indetermination remains in its core as the opposite, the other of an old world in which reality would have disappeared. Deleuze goes further than Baudrillard while avoiding a dead end or a nostalgic speech in which the illusion would have been installed in stages. The illusion has always already existed since it is as Marx had already noticed imbedded in vision itself. Vision transforms a world, which is itself becoming. Vision is becoming of becoming. It is therefore possible to escape the choice between naive realism and deadly illusion. The book itself is becoming, becoming film. A deterritorialization and reterritorialization which generates a metamorphosed Remy, closer to a kangaroo through Rose's eyes, machine, becoming Gwyneth, becoming Rose “in Sylvia's skin" (115): "Rose looks at me as if I was a kangaroo in a blueberry field." (105). The moving image has become a writer and the writer, an animal. Remy is also metamorphosed in his role as a father: "I was a very bad father" (208), more aware of his own mistakes: "Because of me, Carole left with my married life. / Because of me, Alexander left with my life. / Because of me, I am nothing" (117), nothing but a moving image, a line of flight.

Following the moving images, the lines of flight, sometimes referred to 
as "lines", "songs of trails" (105) "sign of trail" (112), allows for the recreation of a territory non territorializing which allows movement in all directions. The moving image has become wild and has turned into a writer while the poet became a wild animal "whose chain just broke" (121). The lines of flight create potential of being affected and affecting, allowing for a potential "transfiguration" (113), or "actualization of possibilities [...] in flesh and bones" or "incarnation" (202), or "apparition" or even a "virtuality momentarily actualized." (76)

To conclude, the text is not illustrated by a picture, but it is shaped to better represent the movement within it. The screen or white page is no longer just a reproduction surface, but it is a space where transformations occur. Just like Remy who "pauses, amazed to find in the language some forms that respond to what our senses have apprehended" (28), the spectator-reader pauses amazed to read a story with "an air of deja-vu." (190) The filmography at the end of the novel does not give all the keys for all the films alluded to in the novel, the reader-viewer then searches for film images as if he was in a treasure hunt. Passive spectator, he has become emancipated and won't indulge in an easy reading in which all the keys would have been given to him in advance. Images introducing movement are no longer archetypes, and are charged with a dynamic tension. The question is when art is generated by a machine, be it a GPS or a camera, a constraint (Oulipo), or a software (hypertext, video games ${ }^{27} .$. ), is it still literature? Could this phenomenon be assimilated to an abandonment of the most human part of us? Simplifying the world, that is to say reducing it to a calculated mechanism, seems at the same time reassuring and dangerous ${ }^{28}$. The narrator expresses this paradox many times especially when he affirms: "it is a very reassuring conception of the world [...] everything is controlled, domesticated and predictable, if only life could be that simple." (29) Everything is indeed becoming (Deleuze), but it does not mean that one should renounce and give up on art in the name of the unrepresentable or rules of "appropriateness between a particular subject and a particular form" (Rancière, 2007: 118). The inevitable growing of visual media in modern society is a phenomenon that only allows renewing literary texts. If this novel is the story of an inspiration crisis, it does not conclude in helplessness, which is precisely what the narrator announces at the very beginning: "I do not like to be told 
that I will be forever lost. It sounds apocalyptic' (9). Contrary to his body machine (not working up to his expectations), the other machine (literature or GPS) is performing beyond all expectations. Gervais' kinetic creation gives access to an infinity of readings calling for a cinematic collective memory filled with images from "a certain souvenir, emotion or perception" (Deleuze, 1986: 8). Even if we are living in an area of incredible alienation, technique is not to be the enemy of the living.

If cinema, mid-way between art and industry, seems to be the perfect example of a modern art, showing a world image to a subject spectator, Deleuze shows that on the contrary, it is a world of images radically independent from any subjective representation. Cinema is what allows us to go beyond the classical opposition between the order of consciousness and the order of things, to go beyond the alternative of an idealistic or a materialistic conception of the world ${ }^{29}$. This double position is no longer possible since there are at the same time more images in the material world and movements in consciousness. Those movements in consciousness seem to be also what the narrator in Gervais' book is understanding when he affirms that an image is living in him as much as he is "haunting it" (107). What is haunting in this book are the movement-images from all the movies edited together in a book / film or "like a film", and just like Remy in the scene in the basement, we are spectators / readers witnessing our own miracle, and remembering that this is also already a scene from another movie with Gwyneth Paltrow, a movie entitled Great Expectations of course.

\section{References}

A Perfect Murder.Dir. Andrew Davis.Perf. Gwyneth Paltrow. Warner Bros, 1998. Agamben, G. (2002).Difference and Repetition: On Guy Debord's Films. In: McDonough, Tom. Guy Debord and the Situationist International: Texts and Documents: Cambridge, MA: MIT. Print.

Baetens, J. (2010)."Expanding the Field of Constraint: Novelization as an Example of Multiply Constrained Writing."Poetics Today 31.1: 51-79. Print. Barthelme, D. (1975). The Dead Father. New York: Farrar, Straus and Giroux. Print.

Barton Fink.(1991).Dir. Joel and Ethan Coen.

Baudrillard, J (1981). Simulacres et Simulation. Paris: Galilée. 
HSS, vol. V, no. 1(2016): 53-72

Bergson, H., and A. Mitchell.(1913). Creative Evolution. New York: H. Holt and. Print.

Debord, G. "Text Archives Situationist International Texts the Society of the Spectacle."Situationist International Online.N.p., n.d. Web. 11 Aug. 2013.

Debord, G.(1997).Panégyrique.Vol. 2. Paris: Fayard. Print.

Deleuze, G. (1988). Interview of Gilles Deleuze with Raymond Bellour and Francois Ewald« Signes et événement », in Le Magazine Littéraire. Print.

Deleuze, G. (1986).Cinema 1: The Movement-image. London: Athlone. Print.

Deleuze, G., and F. Guattari.(1980).Mille Plateaux. Paris: Éditions De Minuit. Print.

Deleuze, G., and F. Guattari. (1991).Qu'est-ce Que La Philosophie?Paris: Editions De Minuit. Print.

Derrida, J., and B. Stiegler. (1996).Echographies De La Télévision: Entretiens Filmés. Paris: Galilée. Print.

Gervais, B. (2010).Comme Dans Un Film Des Frères Coen: Roman. [Montréal]: XYZ Éditeur. Print.

Great Expectations. Dir. Alfonso Cuarón. Perf. GwynethPaltrow. 1998.

Lippit, A. M. (2000).Electric Animal: Toward a Rhetoric of Wildlife. Minneapolis: University of Minnesota. Print.

The Man Who Wasn't There.Dir. J. and E. Coen. 2001.

Mallarmé, S., and B.Marchal. (2003).Oeuvres Complètes.Paris: Gallimard. Print.

Mitchell, W. J. T. (1994).Picture Theory: Essays on Verbal and Visual Representation. Chicago: University of Chicago. Print.

Rancière, J. (2007). The Future of the Image. London: Verso. Print.

The Royal Tenenbaums.Dir. Wes Anderson.Perf. Gwyneth Paltrow. 2001.

Sylvia. Dir. Christine Jeffs.Perf. Gwyneth Paltrow. 2003.

The Talented Mr. Ripley. Dir. A.Minghella. Perf. Gwyneth Paltrow. 1999.

View from the Top. Dir. B.Barreto. Perf. Gwyneth Paltrow. Miramax Films, 2003.

${ }^{1}$ Gervais, B. Comme Dans Un Film Des Frères Coen: Roman. Montréal: XYZ éditeur, 2010. All translations from French to English are my own.

${ }^{2}$ See Baetens, J. "Expanding the Field of Constraint: Novelization as an Example of Multiply Constrained Writing." Poetics Today 31.1 (2010): 51-79.

${ }^{3}$ Barton Fink is the main character from the movie of the same name by the Coen brothers; Barton is a scriptwriter for Hollywood in desperate need of some inspiration.

${ }^{4}$ Argyle Street is also the name of a famous street in Chicago where the Essanay Studios were located, best known for the production of some Charlie Chaplin 
HSS, vol. V, no. 1(2016): 53-72

comedies and Broncho Billy westerns.

${ }^{5}$ His wife "Carole" reminds us of Gwyneth Paltrow playing the role of Carol Ann Fagot Applegarth Holland in the movie Deadly Relations. Perf. Gwyneth Paltrow. ABC, 1993.

${ }^{6}$ The Man Who Wasn't There.Dir. J. Coen and E. Coen. 2001.

${ }^{7}$ Gwyneth plays a flight attendant in the movie View from the Top.

${ }^{8}$ Estelle A. is a reminder of the character Estella played by Gwyneth Paltrow in the movie Great Expectations, a 1998 adaptation of Charles Dickens novel of the same name by AlfonsoCuarón.

${ }^{9}$ The American poet Sylvia Plath was portrayed by Gwyneth Paltrow in the movie entitled Sylvia.

${ }^{10}$ In that regard, the work ofW.J.T. Mitchell entitled Picture Theory: Essays on Verbal and Visual Representationanalyses the iconophobia resulting from the assumption that speech needs to be protected from the raising of images.

${ }^{11}$ His notebooks or journals where he records and keeps many of his thoughts and souvenirs.

${ }^{12}$ In French, the Anglicism "Has been" is often used to describe someone who is no longer famous and popular.

13 The Dead Father also makes interesting use of white space, with graphs throughout the first half and a "manual for sons" in the middle.

${ }^{14}$ He has gigantic dimensions, he is articulated, and he has mechanical leg.

${ }^{15}$ Such as the dinner with friends to borrow the example of the film The discreet charm of the bourgeoisie.

16 "Sur le vif' could be translated as 'on the spot' or 'from life', therefore "capturer sur le vif' would mean 'to catch alive' that is to catch the movement itself.

${ }^{17}$ The contamination between words and animated images allows Gervais to access new worlds and to see from another perspective than the subjective one. This perspective is in line with new developments on the question of the animal. Authors such as Gilles Deleuze and more recently the speculative realists, emphasize the hypocrisy of the late discourse in contemporary modernity which promotes correlationism. According to them, human finitude no longer limits the speech. It becomes imperative to operate a rethinking of our positioning as human in the world.

${ }^{18}$ My own translation.

${ }^{19}$ In line with Deleuze thesis on Cinema as a medium capable of the production of the new.

${ }^{20}$ OuLiPo "Ouvroir de LitteratureFrancaise".

${ }^{21}$ My own translation. 
HSS, vol. V, no. 1(2016): 53-72

${ }^{22}$ Jan Baetens in his article "Expanding the Field of Constraint" sees novelization as a form of constrained writing.

${ }^{23}$ For Debord, it is a possibility especially with the contradiction concept that he develops in his essay the Society of the Spectacle.

${ }^{24}$ My own translation.

${ }^{25}$ My own translation.

${ }^{26}$ Of course a movie with Paltrow comes to mind, A Perfect Murder. Dir. Andrew Davis.Perf. Gwyneth Paltrow.

${ }^{27}$ In fact at the beginning of their adventure in Australia Carole and Remy compare their GPS to a video game: "it is like in a video game" (9).

${ }^{28}$ The book front cover is very revealing of that tension. There are two photographs of a young blond girl sitting on a bed. On the first she is showing an apple, only the apple is clear and her image is blurry, but on the other picture, both apple and the girl are clear as she is about to take a bite of that apple.

${ }^{29}$ See on that note the movement in contemporary philosophy called Speculative realism and in particular the book from Quentin Meillassoux entitled After Finitude: An Essay on the Necessity of Contingency.Bloomsbury Academic, 2010.

\section{Biographical note}

Valerie Hastingsearned her Ph.D at SUNY Buffalo and is the author of "Je mange donc je suis. Le dédoublement du 'je' dans Le Mangeur de Ying Chen" for the thematic number entitled Protean Selves: First-Person Narrators in Twenty-FirstCentury French and Francophone Fiction for Cambridge Scholars Publishing. Her dissertation, Les formes de l'humaindans la fiction francophone contemporaine, focuses on the narrative process of metamorphosis in contemporary Francophone works as a way to express the unspeakable and in light with the morphing principle at work as the core process of any "motion picture." She currently is Assistant Professor in the Department of Modern and Classical Languages at the University of North Georgia (UNG). 